\title{
Optimal Design of Hybrid Power Generation System to Ensure Reliable Power Supply to the Health Center at Umm Jamal, Mafraq, Jordan
}

\author{
Ahmad Bataineh $^{1}$, Amin Alqudah ${ }^{2} \&$ Abedalgany Athamneh ${ }^{3}$ \\ ${ }^{1}$ Electrical and Electronics Eng. Dept., Al-Huson University College, Al-Balq'a Applied University, Jordan \\ ${ }^{2}$ Computer Engineering Dept. Hijjawi College, Yarmouk University, Jordan \\ ${ }^{3}$ Electrical Power Engineering Dept. Hijjawi College, Yarmouk University, Jordan \\ Correspondence: Ahmad Bataineh, Electrical and Electronics Eng. Dept., Al-Huson University College, \\ Al-Balq'a Applied University, Jordan. Tel: 962-2701-0400. Fax: 962-2701-0397. E-mail: \\ bataineh@huson.edu.jo
}

Received: April 22, 2014 Accepted: May 23, 2014 Online Published: June 10, 2014

doi:10.5539/eer.v4n3p9 URL: http://dx.doi.org/10.5539/eer.v4n3p9

\begin{abstract}
Remote areas are usually fed from generators that run on diesel. Recently, there is an increasing interest on hybrid renewable energy sources, especially wind and solar energies for their availability and competitive running cost in the Middle East region. The hybrid renewable energy generation systems usually have two or more different generation (or storage) sources of different types to secure a continuous supply for the electrical loads.

The paper presents a case study of a remote health center which operates 24 hours a day, and shows the importance of relying on renewable energy systems. The system considered consists of Wind Turbine, Batteries, photovoltaic, and conventional diesel generator to feed a load variable at a rate of $55 \mathrm{kWh} /$ day with $5.9 \mathrm{~kW}$ peak load. The study is based on real data of wind speed and solar radiation obtained from official authorities. The various available options are compared technically and economically using a HOMER software package. The optimal reliable system is selected and the capacity of the system components is specified.
\end{abstract}

Keywords: hybrid system, renewable energy, reliable power system, optimal system design

\section{Introduction}

Energy has vital role to play in the wheel of evolution and modernization of different communities. It is one of the most important requirements of economical and social sectors and considered as the most essential component that elevates the standard of public life. The relationship of energy to various sectors is complementary threaded and it influences the levels of development in all fields positively when provided with high specifications and negatively otherwise.

There was a large amount of research and work in the recent decades on the development of renewable energy sources with emphasis on hybrid systems. Renewable energy sources are promising in providing economical and sustainable energy systems. Those systems are environmentally friendly due to many reasons including: the increasing global energy demand and the associated pollution produced, the sharp increase in the prices of petroleum products and their unstable prices and supply.

Distributed generation (DG) is an emerging approach in the electricity sector, which represents good alternatives for electricity supply instead of the conventional centralized power generation approach. The DG operating model has drawn strong interest because of its potential to increase system capacity at lower cost. These DG systems are capable of combining different types of power sources such as gas or petroleum fuels, renewable sources in an efficient, reliable, and flexible. Moreover, DG systems have features that help to secure network solutions for the electrical loads. It is worth mentioning that DG refers to any technology used to generate electrical power that is integrated within the distribution system and close to the load site. The generators are connected to the low or medium voltage network and are not planned in central manner (Angelopoulos, 2004). 
Distributed generation systems are generally based on renewable sources. Hence, they can play a major role in the field of energy security by reducing the dependence on outside country imported fuel (Samantha, 2007).

DG can be used separately to provide electricity for the local consumer and it is possible to connect them with the public electricity grid to contribute a portion of the electric power demand. It is possible for the distributed generation systems to operate on renewable energy or fossil fuels or by using the waste heat (Samantha, 2007).

Diesel-powered electrical generators are usually used for supplying of the remote areas. Recently, there is an increasing interest on securing electric system based on renewable energy sources, especially wind and solar energy.

The hybrid systems are getting more important for several reasons; the main one is its capability to secure the continuity of feeding the load with electric power in different operating conditions, and its optimum utilization for available resources in remote areas. In addition, the economical factor plays an important role where the cost of some hybrid systems are far below than that of using a single type power generation system.

\section{Literature Review}

Hybrid power generation is a hot topic in renewable engineering systems. Many people have worked in this filed. Below is a summary of the most relevant work in the literature.

In (Trazouei, 2013), optimal design of a hybrid solar-wind-diesel power system to electrify rural areas using imperialist competitive algorithm was designed. Some artificial intelligence optimization techniques were presented as well. The ultimate goal was to minimize the net cost of the hybrid system for 20 years. The imperialist competitive algorithm was shown to be the fastest and the most accurate.

In (Oğuz, 2012), isolated wind-photovoltaic hybrid power system with battery storage was presented and supposed to be able to supply electricity to two laboratories with a peak electrical load of $1072 \mathrm{~W}$. Statistical comparisons were performed to compare between the energy generated and the energy consumed. Monthly data were obtained and compared, and as a result of the comparison, it was shown that the generated power was above the consumed power.

In (Godson, 2013), a Solar-Wind hybrid power system was presented. The system was controlled based on micro controller. This assures optimum resource utilization and efficiency improvement as compared with their individual mode of generation. It also makes the system more reliable and dependable.

In (Salmani, 2014), several hybrid energy system models were analyzed. HOMER software was used to evaluate the systems and a remote island was taken into consideration to study the most cost effective configuration.

In (Rashidi, 2012), the focus was on the optimal design of a solar-hydrogen hybrid based standalone system. The main goal was to achieve a minimum cost during 20 years system life. Two different configurations for fuel cell and photovoltaic hybrid system were considered. The two configurations were studied and optimized using Fuzzy Particle Swarm Optimization Algorithm where the main target was the efficiency and the cost.

In (Anayochukwu, 2013), the hybridization of diesel generator source system with renewable energy sources was explored and demonstrated. Results showed the possibility of renewable energy to substitute diesel as a source of power. This hybridization idea came to reduce the operation cost and air pollution.

In (Shivrath, 2012), a solar and wind hybrid system was optimally designed for a remotely drip irrigation system. Cost optimization of the wind-solar hybrid system was taken into consideration to provide functional guidelines for the manufacturers of small scale wind-solar hybrid systems.

In (Anagreh, 2013), the feasibility analysis of renewable energy supply options electrifying a small hotel was presented. The paper investigated both technical and economical aspects. The paper showed that on-grid small wind turbine scheme was the most realistic supply option. The paper also showed that the Net Present Cost (NPC) of grid-connected wind energy scheme decreases when the carbon tax increases. The paper concluded that the implementation of the wind and hybrid wind/solar energy resources will increase in the future.

In (Khare, 2013), a methodology for calculating the sizing and optimizing a stand-alone SPV/diesel/battery hybrid system was developed. The methodology used particle swarm optimization algorithm to minimize the system cost. The work is applicable in the cases where reliable hybrid SPV/diesel system for small railway station is required.

In (Fahmy, 2012), the goal was to design an optimal economic renewable energy system. The paper presented four systems namely: Photovoltaic-wind hybrid system, stand-alone photovoltaic system, stand-alone wind system and Photovoltaic -wind-fuel cell hybrid system. The paper showed that the Photovoltaic-wind hybrid system is more suitable than the other systems. 
In this paper we present a case study of the economic feasibility of using a hybrid renewable energy system to supply electric power to loads in remote areas and compare it with a conventional system. We consider a hybrid system consisting of a photovoltaic panels, batteries, wind turbine and diesel generator to provide richness for the electrical loads at a rate of $55 \mathrm{~kW}$ hours/day with $5.9 \mathrm{~kW}$ peak load throughout the day (24 hours). We adopted real data for the site which is a health center at Umm Jamal / Mafraq - Jordan. We performed a technical and economical analysis using the HOMER software (Laboratory N, 2014) which is a computer optimization model developed by the U.S. National Renewable Energy Laboratory (NREL). It is used to assist in the design of micro-power systems and to facilitate the comparison of power generation technologies across a wide range of applications. It can model the physical behavior of a power system and its total cost, which is the cost of installing and operating the system. It should be noted that HOMER allows the modeler to compare many different design options based on their technical and economic merits. It also assists in understanding and quantifying the effects of uncertainty or changes in the inputs to secure the power supply to the load, compare different options, select the optimum design. The capacity of the system components are determined so as to achieve the best reliability of the system with a flow of electrical energy that is secure, continuous, and low price (Laboratory N, 2014).

\section{Renewable Energy Generation Systems (Hybrid)}

\subsection{Importance of the Hybrid System}

Hybrid power supply systems consist of different energy sources in order to have more secured supply of electrical loads with increased reliability and durability of the system. The hybrid systems take advantage of the strengths of the subsystems to overcome the weaknesses of the individual systems. The features of the hybrid systems are mainly more reliable and less expensive than the conventional systems, because the solar sources are available during the day while the wind energy is 24 hours a day (Dunlop, 2010). It should be noted that wind and solar energy sources are practically free after the installation of their infrastructure. An efficient management or control system can determine the power flow to the loads from various components of the hybrid system during the period of operation. Note that in a hybrid system, the individual power sources are operating like a team supporting each other in a highly reliable manner. It is obvious that when the energy is drawn from the solar subsystem, the other subsystems can be viewed as standby systems.

\subsection{Components the Hybrid System}

A typical hybrid power generation system consists of various components as shown in Figure 1. The components can be summarized and described as follows:

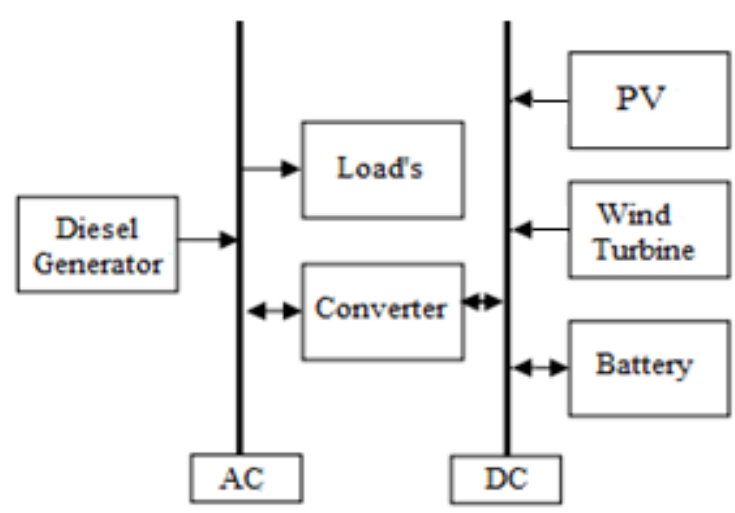

Figure 1. Hybrid power generation system

\subsubsection{Photovoltaic's (PV)}

Photovoltaic's (PV) is a solar energy technology that uses the unique properties of semiconductors to directly convert solar radiation into electricity (Dunlop, 2010). Many advantages and benefits add the value to PV systems beyond the potential economic savings. Photovoltaic's is an environmentally friendly technology that causes no noise or pollution and can be installed on the site in short period of time. Moreover, PVs are durable and rarely require maintenance and can be dislocated easily (Dunlop, 2010; Patel, 1999). Currently, the most significant disadvantage of $\mathrm{PV}$ systems is the high initial cost compared to prices for competing 
power-generating technologies. According to the improvements for cell efficiencies and manufacturing methods, a reduction in PV system cost is experienced, higher costs for conventional electricity-generating technologies help make PV and other renewable energy sources as a serious competitive alternative system that are more cost-effective (Dunlop, 2010).

\subsubsection{Wind Turbines (WT)}

Power generation by wind is comprised of one or more units, operating electrically in parallel which consists of different components such as towers, wind turbines with blades, a yaw mechanism, a mechanical gear, an electrical generator, and speed sensors and controllers (Patel, 1999).

Because of the large moment of inertia of the rotor, the design challenges include the starting, the speed control during the power producing operation, and stopping the turbine when required. The eddy current or other type of brake is used to halt the turbine when needed for emergency or for routine maintenance. In the multiple tower wind farm, each turbine must have its own control system for operational and safety functions from a remote location (Patel, 1999).

\subsubsection{Batteries}

One disadvantage of electricity is that it cannot be easily stored on a large scale. Almost all electrical energy used today is consumed as it is generated. This poses no hardship in conventional power plants, where the fuel consumption is varied with the load requirements. The solar radiation and wind, being intermittent sources of power, cannot meet the load demand all of the time, 24 hours a day (Patel, 1999). The energy storage, therefore, is a desired feature to incorporate with renewable power units, particularly in stand-alone plants. It can significantly improve the load availability, the key requirement for any power system. Electrochemical batteries are the most convenient present and future energy storage technology that is considered for stand-alone photovoltaic or wind power systems. Batteries are the most widely used devices for energy storage in a variety of applications (Patel, 1999).

There are two basic types of electrochemical batteries (Patel, 1999):

- The primary battery, which converts the chemical energy into the electrical energy.

- The secondary battery, which is also known as the rechargeable battery.

The batteries as energy storage systems contribute to the stability of the hybrid system. They are intended to support the supply output and maintain it fixed and stable despite fluctuating electrical load, and provide energy to overcome the shortage of the main sources intraday (as sources of sun, wind and hydro) (Patel, 1999; Farret, 2006).

\subsubsection{Power Converter and Control Units}

An essential component of the hybrid system is the power converted needed to perform AC/DC, as well as DC/AC power conversion (Patel, 1999). The control units are the brain of the system and its components. Their objective is to manage and control the components of the hybrid system at the best possible manner. The control units are sophisticated and operated by computers (Patel, 1999).

\subsubsection{Electrical Generators}

The inclusion of electrical generators in the hybrid system increases its reliability and availability. Most of the small electrical generators use a gasoline engine as the mechanical prime mover, methane, propane and diesel powered engines can also be used. A number of factors will affect the selection process, including initial cost, power requirements, fuel availability and maintenance requirements (Ventre, 2005).

\section{Cost Optimization}

The aim of this study is to achieve a stand-alone hybrid generation system, which should be appropriately designed in terms of economic, reliability, and environmental measurements for physical and operational constraints/strategies (Salmani, 2014).

The system cost is defined as sum of $\mathrm{PV} \cos t\left(\mathrm{C}_{P V}\right)$, WG cost $\left(\mathrm{C}_{W G}\right)$, battery cost $\left(\mathrm{C}_{B A T}\right)$, electrolyses cost $\left(\mathrm{C}_{E L E C}\right)$, Fixed cost $\left(\mathrm{C}_{F}\right)$, convertor cost $\left(\mathrm{C}_{C O N V}\right)$, and hydrogen tank cost $\left(\mathrm{C}_{\text {TANK }}\right)$.

$$
C_{S Y S T E M}=C_{P V}+C_{W G}+C_{B A T}+C_{E L E C}+C_{F}+C_{C O N V}+C_{T A N K}
$$

The cost for each element should be deducted:

$$
\mathrm{C}_{i}=\mathrm{N}_{i} *\left[\mathrm{C}_{\text {Costi }}+\mathrm{R}_{\text {Costi }} * \mathrm{~K}_{i}+\mathrm{O} \& \mathrm{M}_{\text {Costi }}\right]
$$


$\mathrm{i}=\mathrm{PV}, \mathrm{WG}$, Battery, FC, Electrolyses, where $\mathrm{N}_{i}$ is the number/size of the system component, $\mathrm{C}_{\text {Costi }}$ is the capital cost, $\mathrm{R}_{\text {Costi }}$ is the replacement cost, $\mathrm{K}_{i}$ is the number of replacement, and $\mathrm{O} \& \mathrm{M}_{\text {Costi }}$ is operation and maintenance cost through the system operation (Salmani, 2014).

\section{Case Study of a Hybrid System}

To choose the best design suited for the case of operation of the hybrid system, the electrical load need a proper and detailed study in terms of its nature, amount, pattern, and relationship with time. As one of the important components of the design, it is necessary to determine the amount of load loss allowed as it is one of the important components of the design. The available resources in the area (solar or wind sources, etc.) must be evaluated in order to choose the most appropriate source that secures the load power. To assess the sources and select the most appropriate one it is necessary to collect the data related to each of the sources be available. Once the sources are identified, it is important to specify the technological options best suited to these sources. The capacity of each component of the system and the method of optimal connectivity between components can be determined after an evaluation study is completed.

In the case study, the site is a health center that works all days and 24 hours a day in Umm Jamal, Mafraq Governorate area, Jordan. The region and the site exhibit availability of wind sources, bright sun throughout the day and for more than $90 \%$ of the year. The site is located at altitude $682 \mathrm{~m}$ above sea level, on Coordinates $32 " 17 ' \mathrm{~N}$ and 36"21'E (Anagreh, 2011).

Our study is to secure power supply to electrical loads rated $55 \mathrm{kWh} /$ day with $5.9 \mathrm{~kW}$ peak load using a hybrid system (wind - photovoltaic - batteries - diesel generator). The HOMER software provides us with a number of possible solutions. A comparison is conducted between the various possible solutions and the conventional method to select the solution with minimum cost.

\subsection{Wind Speed Data}

We considered an official real data for wind speed taken from Meteorological Department of station Monitoring for a wind station in Mafraq Governorate near to the site to be studied. The data is as indicated in Figure 2 below which shows the average monthly wind speed plotted versus time for the period 2010-2013.

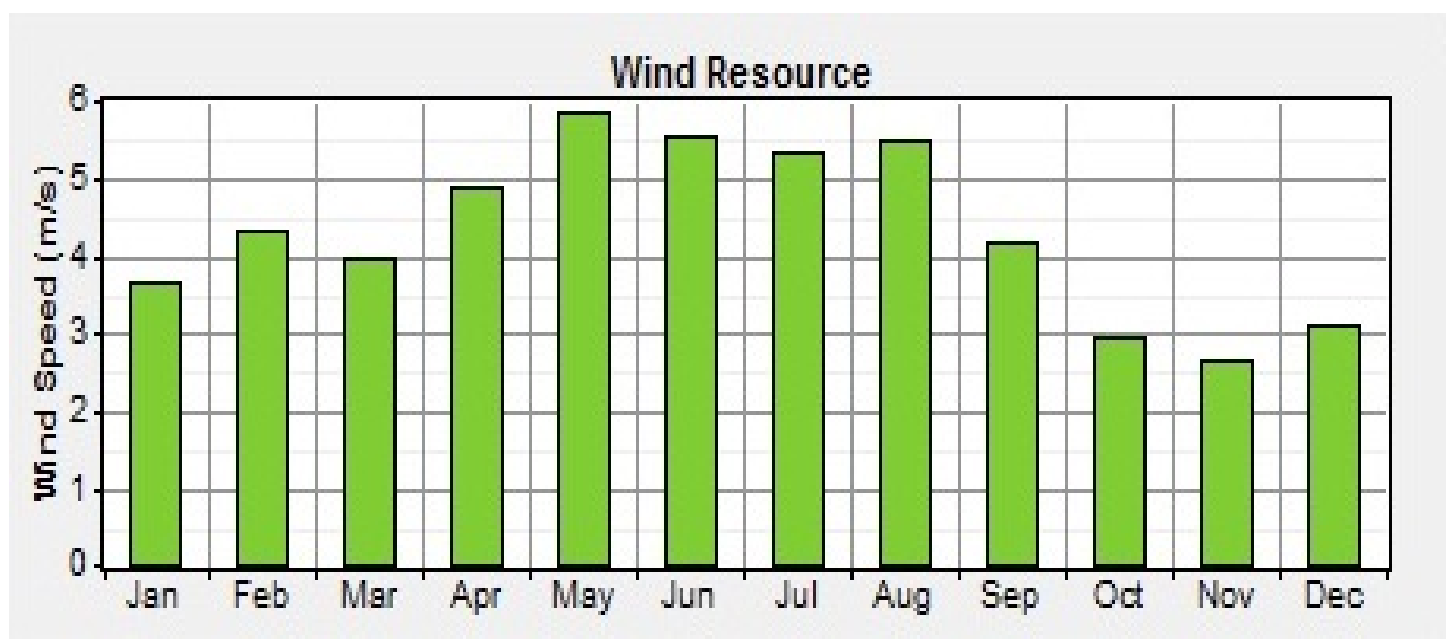

Figure 2. Average monthly wind speed during the period (2010-2013)

\subsection{Solar Radiation Data}

We considered an official real data for solar radiation intensity taken from the neighboring monitoring station in Mafraq Governorate which is a part of the Energy Research Center in Jordan. The data is as indicated in Figure 3 below which shows the daily radiation power density in $\mathrm{kW} / \mathrm{m}^{2} /$ day plotted versus time for the period 2004-2008 (Anagreh, 2011). 


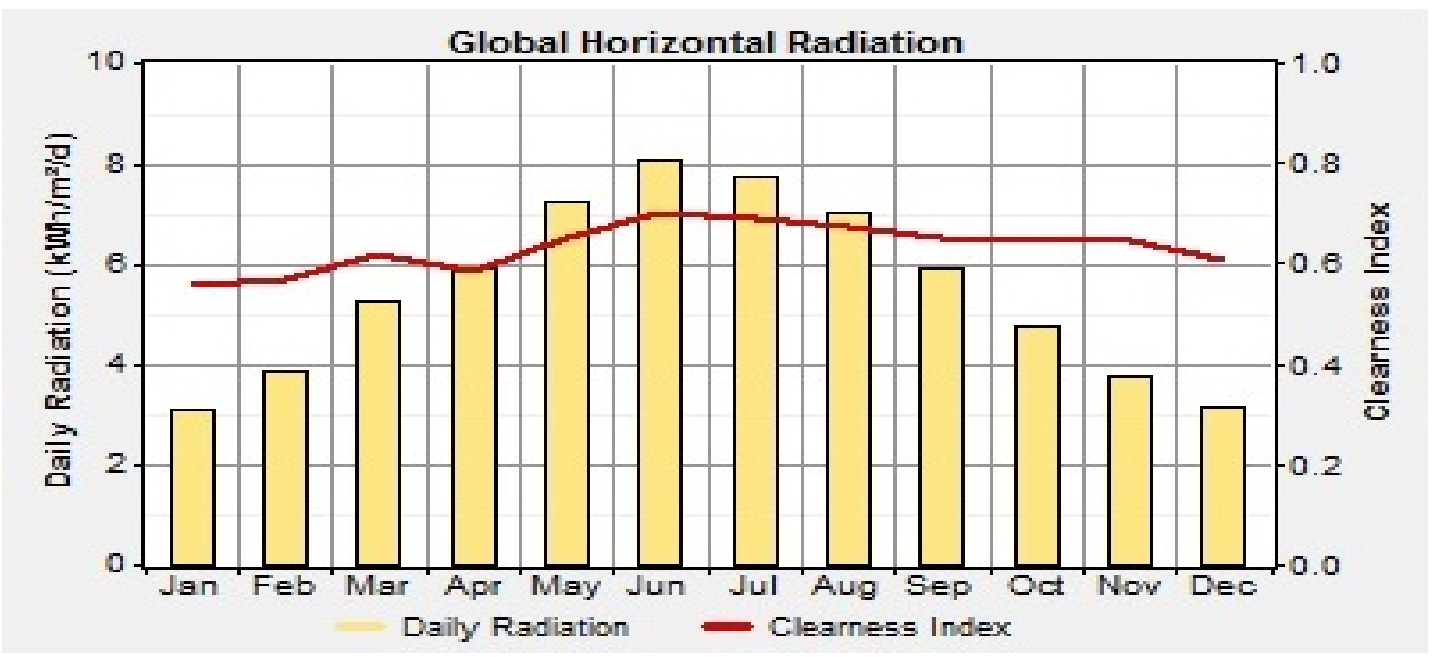

Figure 3. Average monthly solar radiation density during the period (2004-2008)

\subsection{Electrical Load}

The data for electrical loads at the site is taken from Irbid District Electricity Company (IDECO). The average daily profile of electrical load (AC) at the study site is as depicted in Figure 4 which shows the average load in $\mathrm{kW}$ plotted versus time in hours.

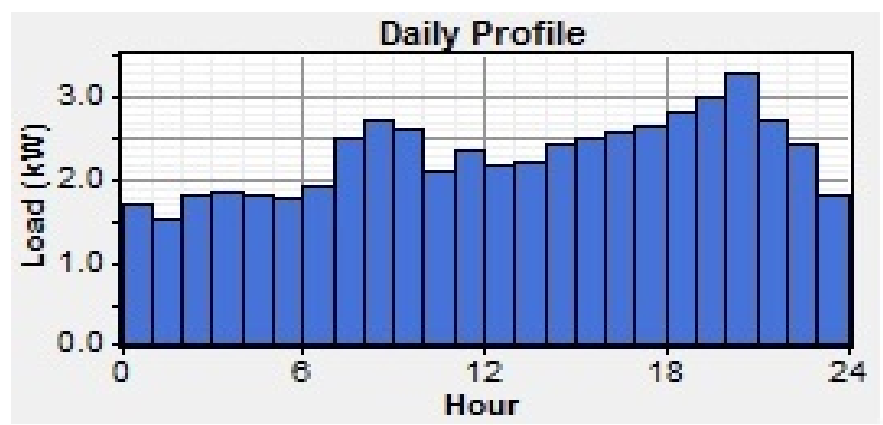

Figure 4. Daily profile of electrical load

The average daily profile of AC electrical load at the study site as varies from month to month is as depicted in Figure 5 which shows the average load in $\mathrm{kW}$ plotted versus time in hours for specific months.

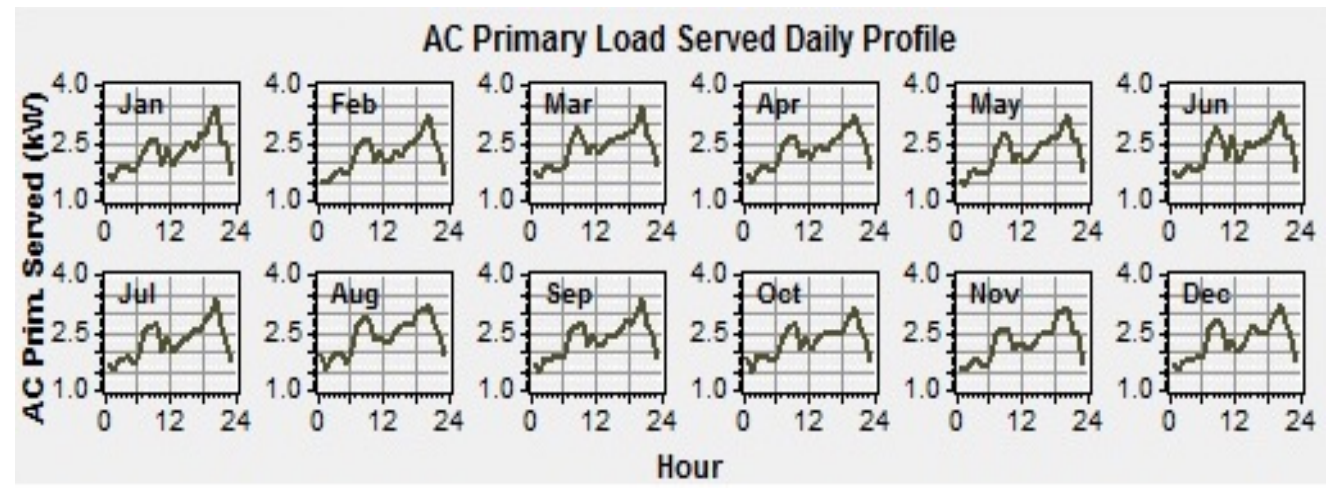

Figure 5. Average load in $\mathrm{kW}$ plotted versus time in hours for all months 
The average monthly energy consumption of AC electrical load at the study site as it varies from month to month is as depicted in Figure 6 which shows the average load in kWh plotted versus months for the period 2010-2013.

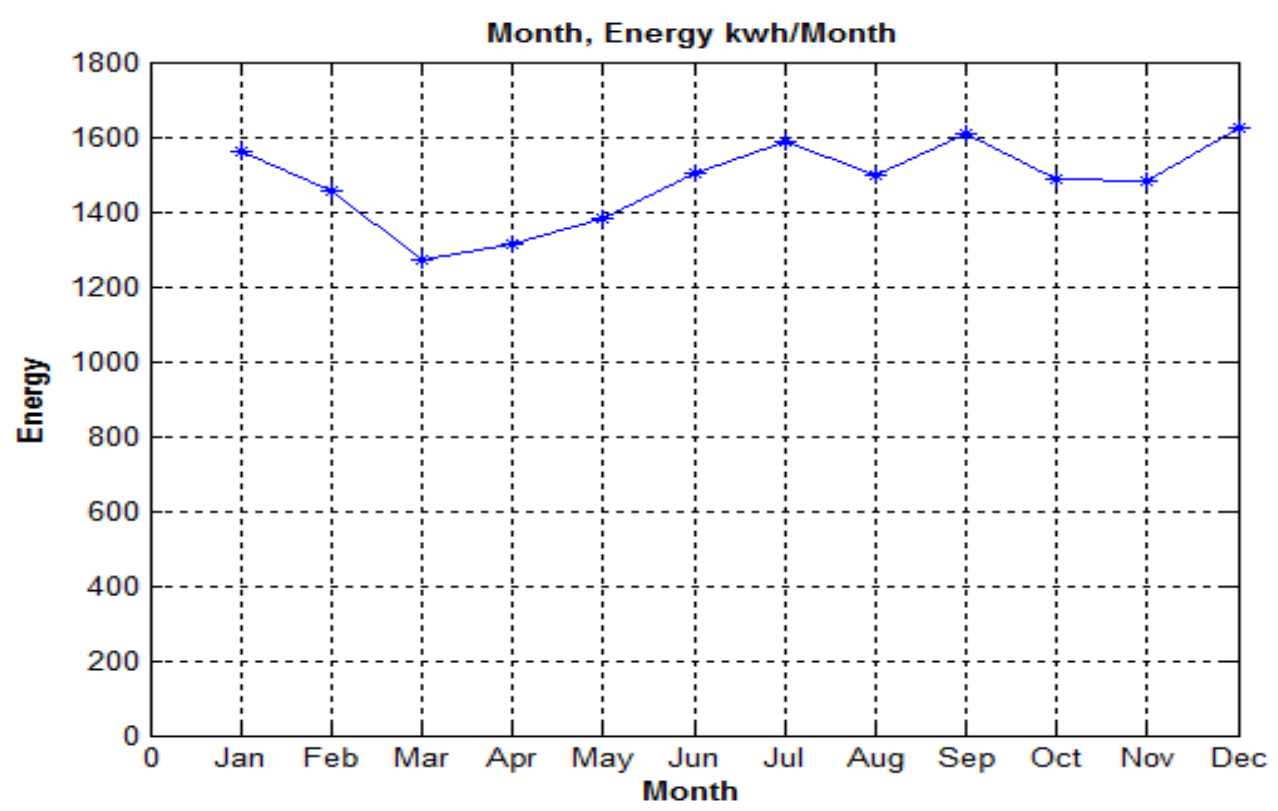

Figure 6. Average energy consumption versus months during the period (2010-2013)

\subsection{Implementation of the Hybrid System}

The implementation and optimal parameters of the hybrid energy generation system are determined using HOMER software. The proposed system comprises primary renewable sources (wind/PV) which are supported by standby secondary conventional sources (diesel generator/batteries). Power converter is included in the system to connect between AC and DC links and the controller unit. HOMER software is also used for pre-feasibility study of the system as well as the sensitivity analysis.

In Figure 7 shown the proposed hybrid system components modeled using HOMER program are as specified below:

a) Wind turbine model SW whisper 500 is used in this system, it has rated capacity of $3 \mathrm{~kW}$ and provides DC. The initial capital, replacement, and operation-maintenance estimated cost of one unit are 9500 U.S.D, 9000 U.S.D and 250 U.S.D/year, respectively. The lifetime of a wind turbine is considered to be 15 years. The power curve of the wind turbine generator is shown in Figure 8 and the details of the wind resource are as shown earlier in Figure 2.

b) The solar PV modules are flexible and can be connected in series, parallel, or both. When the sun rays strike the solar PV panels, it produces electricity. Each module produces $10 \mathrm{~kW}$ of DC power. The solar energy panels are of the fixed type that does not follow the sun direction. The initial capital, replacement, and operation-maintenance costs are 8680 U.S.D, 8000 U.S.D, and 120 U.S.D/year respectively. The lifetime of a PV is taken to be 20 years and the details of the solar radiation resource are shown in Figure 3.

c) The Diesel generator is of the conventional type with capacity $10 \mathrm{~kW}$ and loading rate youngest $30 \%$. The limit fuel consumption is $5 \mathrm{~m}^{3}$ per year and the price of liter is 0.95 U.S.D. The initial capital, replacement, and operation-maintenance cost are 2300 U.S.D, 2000 U.S.D and 2 U.S.D/hr respectively. The expected lifetime of a diesel generator is 15000 hour.

d) The batteries are Hoppecke 12 Opzs 1500 which has a nominal space $2 \mathrm{~V}, 1500 \mathrm{~A}$, and $3 \mathrm{kWh}$. The lifetime of these batteries is 4 years minimum. The single battery initial capital, replacement, and maintenance-operation cost are 508 U.S.D, 475 U.S.D, and 18 U.S.D/year respectively.

e) Power Converter is included in order to maintain the flow of energy between the AC and the DC bus. The input efficiency of the DC/AC inverter is $90 \%$ while the input efficiency of the AC/DC rectifier is 
$85 \%$. The size of the convertor that is used in this system is $10 \mathrm{~kW}$. The initial capital, replacement, and operation-maintenance costs are 3000 U.S.D, 2800 U.S.D and 60 U.S.D/year respectively. The lifetime of the converter is taken to be 15 years.

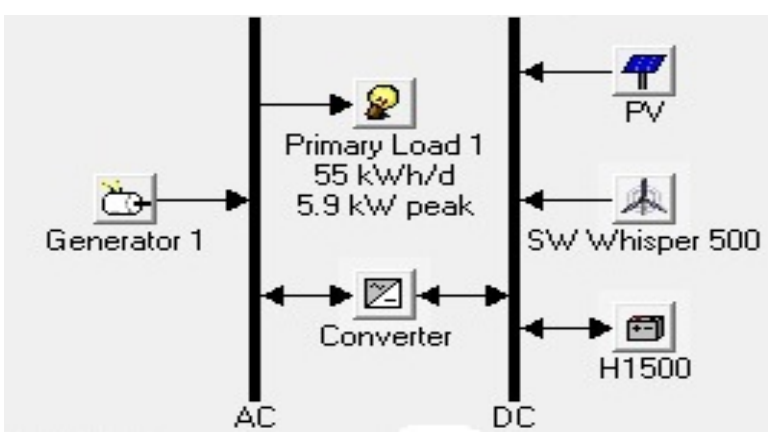

Figure 7. Hybrid system elements and electrical load connection

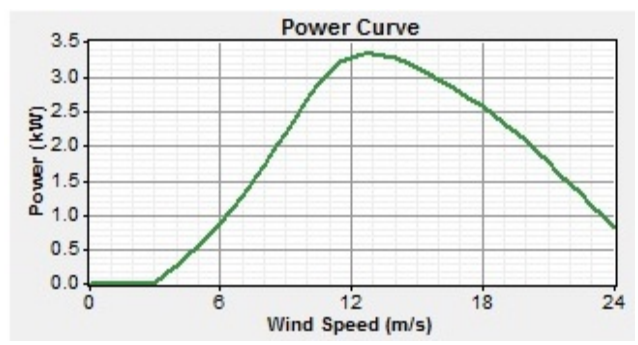

Figure 8. Power curve of the wind generator

\section{Results and Discussion}

Data of wind speed, solar radiation, and the specification of system components are supplied to HOMER Software. Several Simulations were performed to obtain the optimal hybrid system and to determine the proper supply of the electrical power that meets the required load demand at the lowest possible price. Table 1 shows a summary of each variety of the system, including the capacity value of Photovoltaic, wind turbine generator, conventional diesel generator, and batteries, as well as the value of Initial Capital (IC) and Net Present Cost (NPC). The calculated average cost of energy (COE) per $\mathrm{kWh}$ for each combination of the system expressed in U.S. dollars is presented in Table 1. Figure 9 shows the monthly average electric production of the PV and the generator of case 2 mentioned in Table 1. Figure 10 shows the histogram of the cost detail for the same case.

Table 1. HOMER summary of optimization results

\begin{tabular}{|c|c|c|c|c|c|c|c|c|c|}
\hline Case \# & Components & $\begin{array}{l}\text { PV } \\
(\mathrm{kW})\end{array}$ & $\begin{array}{c}\text { WT } \\
\text { W500 } \\
\text { (kW) }\end{array}$ & $\begin{array}{l}\text { GEN } \\
(\mathrm{kW})\end{array}$ & $\begin{array}{l}\text { Battery } \\
\text { H1500 } \\
(\mathrm{kWh})\end{array}$ & $\begin{array}{c}\text { Initial } \\
\text { capital } \\
\text { (U.S.D) }\end{array}$ & $\begin{array}{c}\text { Operating } \\
\text { cost } \\
\text { (U.S.D/yr) }\end{array}$ & $\begin{array}{l}\text { Total } \\
\text { NPC } \\
\text { (U.S.D) }\end{array}$ & $\begin{array}{c}\mathrm{COE} \\
\text { (U.S.D/kWh) }\end{array}$ \\
\hline 1 & PV & 21 & - & - & 162 & 48660 & 1018 & 61673 & 0.240 \\
\hline 2 & PV- GEN & 20 & - & 10 & 108 & 40948 & 1622 & 61677 & 0.240 \\
\hline 3 & PV-WT-GEN & 15 & 3 & 10 & 126 & 49156 & 1713 & 71054 & 0.277 \\
\hline 4 & PV-WT & 21 & 3 & - & 144 & 55112 & 1457 & 73736 & 0.288 \\
\hline 5 & WT-GEN & - & 12 & 10 & 72 & 55492 & 7552 & 152036 & 0.592 \\
\hline 6 & GEN & - & - & 10 & 54 & 14444 & 15677 & 214850 & 0.837 \\
\hline
\end{tabular}




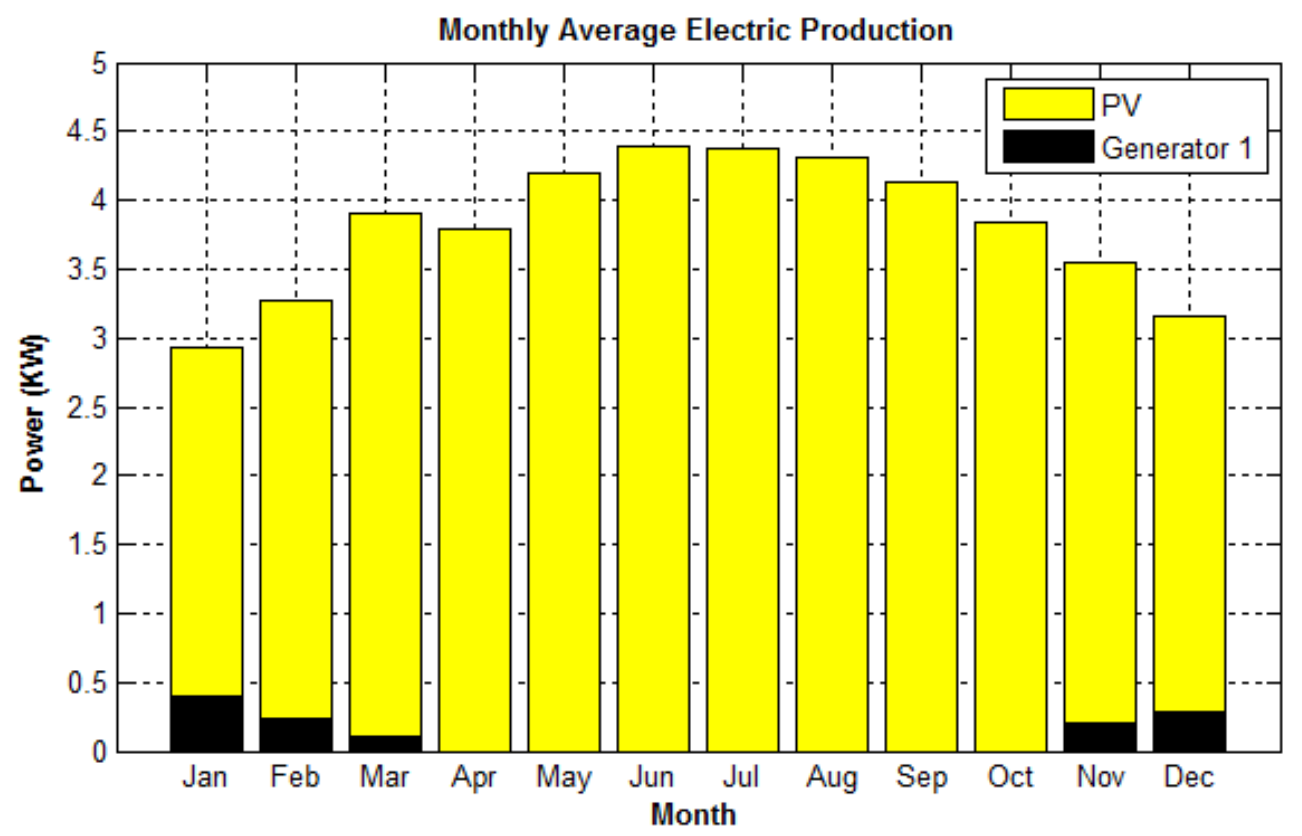

Figure 9. Monthly average electric production (PV \& generator for Case 2)

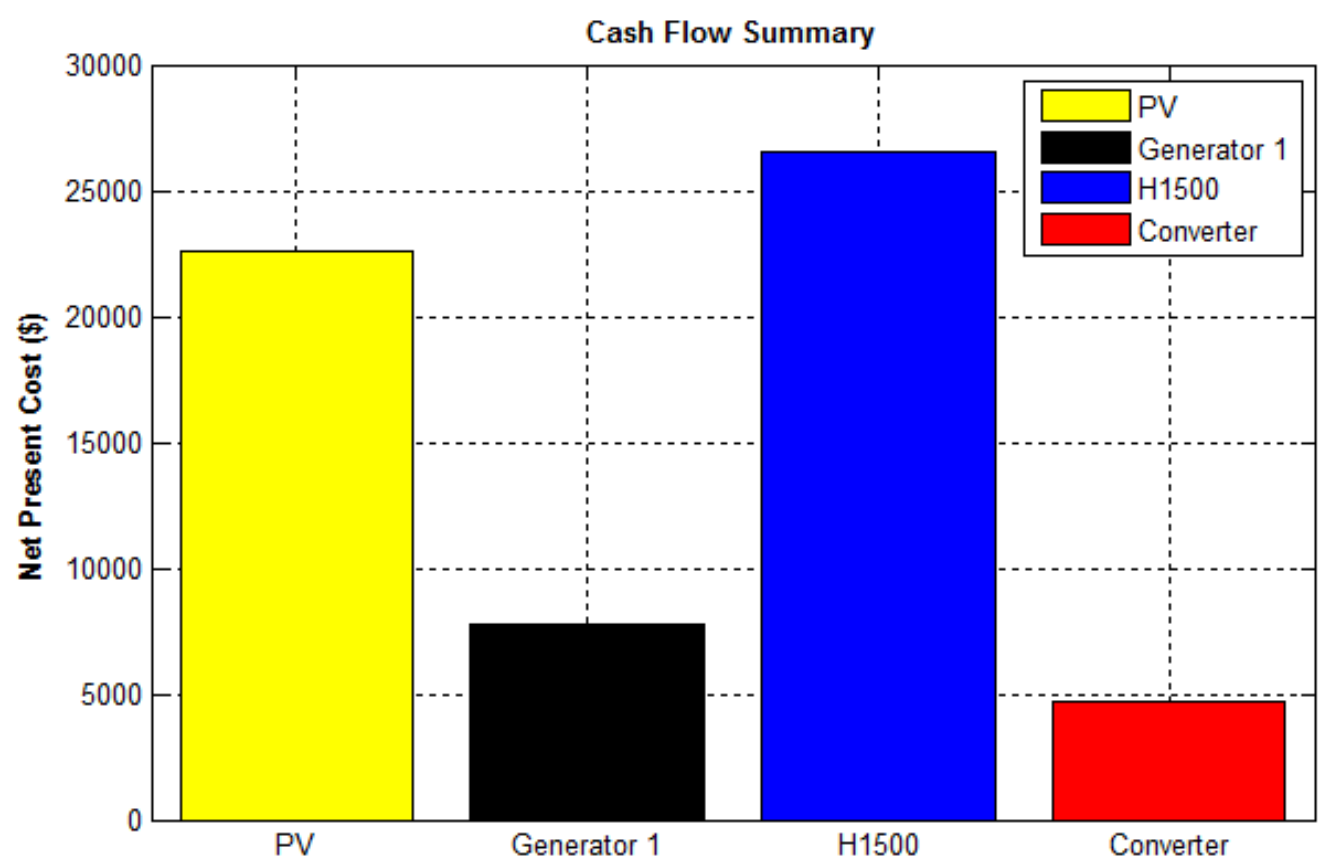

Figure 10. Histogram of cost details (Case 2)

The dialy power profiles of the diesel generator1, PV array, battery charge, and total renewable power daily profile are shown in Figures 11-14, resspectively. 


\section{Generator 1 Electrical Output Daily Profile}

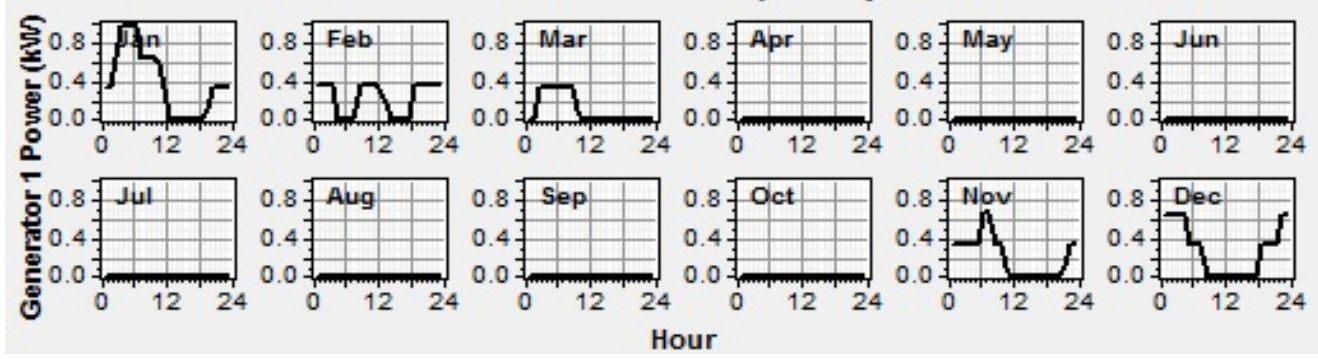

Figure 11. Diesel generator1 output daily profile

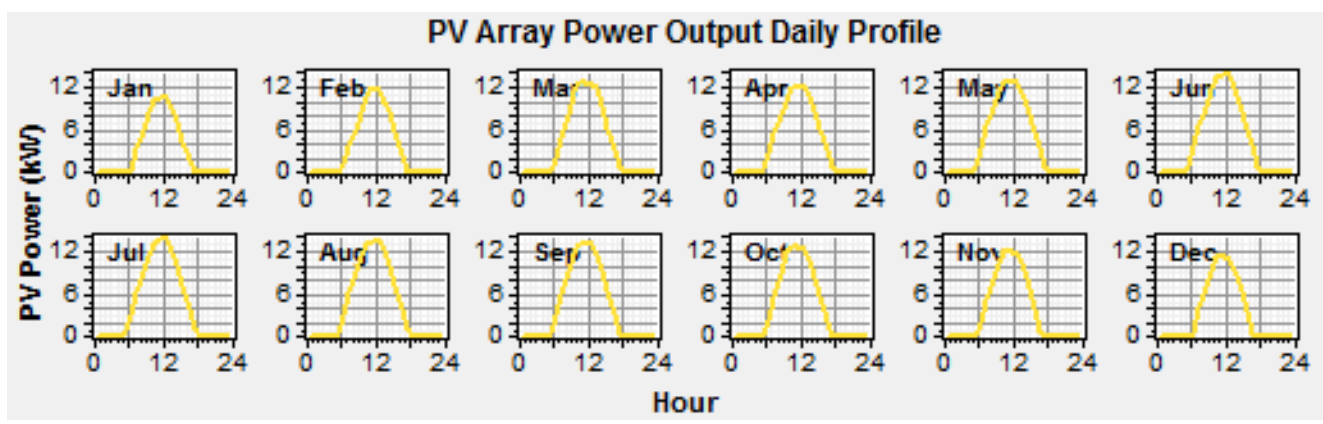

Figure 12 . The PV array daily output power profile

\section{Battery Charge Power Daily Profile}
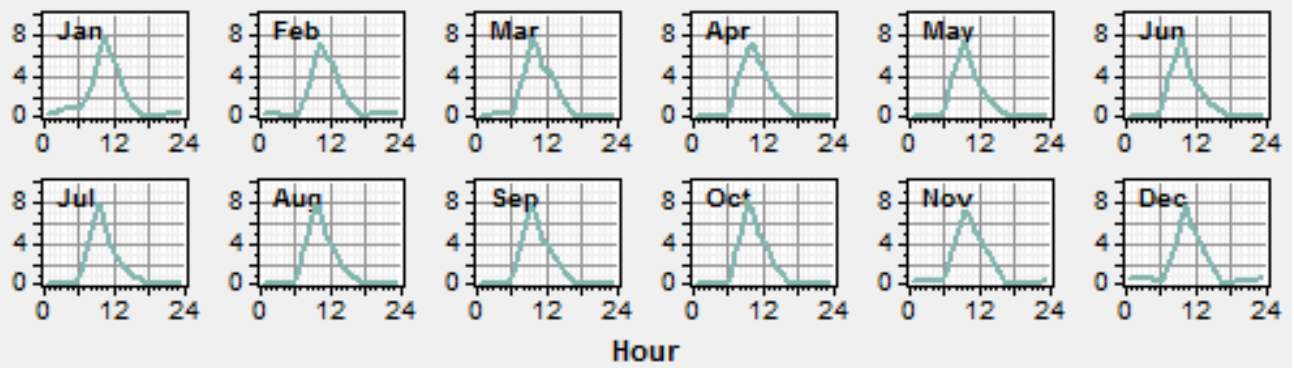

Figure 13. The battery charge power daily profile

Total Renewable Power Output Daily Profile
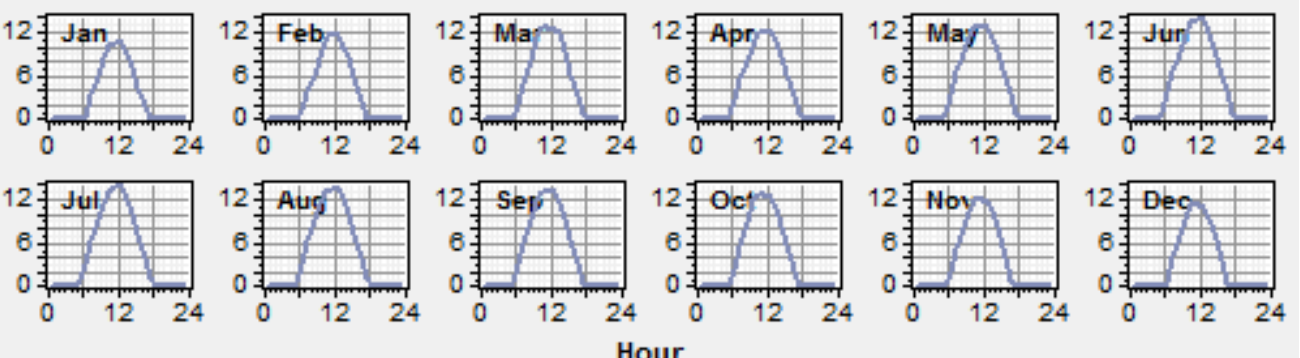

Figure 14 . The total renewable power daily profile

A direct comparison of the economic feasibility results of the system configurations described in Table 1 shows that:

- The hybrid systems labeled as cases 1,2,3, and 4 in Table 1 are the best options available to secure the power supply. 
- The hybrid systems labeled cases 1 and 2 are chosen as optimal hybrid system design for feeding the electrical loads. It is worth mentioning that case 1 consists of photovoltaic system of capacity $21 \mathrm{~kW}$, batteries of $162 \mathrm{~kW}$, while case 2 consists of photovoltaic system of capacity $20 \mathrm{~kW}$, batteries of 108 $\mathrm{kW}$, and a $10 \mathrm{~kW}$ conventional diesel generator.

- Comparing the hybrid systems in cases 1,2 in terms of feeding preference and continuity of electrical power supply, we have chosen case 2 since that net present cost (NPC), and average cost of energy (COE) per $\mathrm{kWh}$ for case 1, 2 are almost equal. The inclusion of conventional diesel generator in the system guarantees its work in very cloudy situations. Moreover, the low capacity and cost of batteries for case $2(108 \mathrm{KW})$ compared to that of case $1(162 \mathrm{KW})$, and initial capital (IC) from 48,660 U.S.D for case 1 to 40,948 U.S.D for case 2.

- It should be noted that the average cost value of power per $\mathrm{kWh}$ for the hybrid systems described in cases 1,2 is equal to $0.240 \mathrm{U} . \mathrm{S} . \mathrm{D} / \mathrm{kWh}$ while the cost of traditional diesel generation system described in case 6 is equal to 0.837 U.S.D/kWh.

\section{Conclusion and Recommendation}

The comparative technical and economical simulation results shows the importance of hybrid systems adopting renewable energy sources for securing power supply to electrical loads in remote areas. Based on the comparative simulation carried using HOMER software, the hybrid system labeled cases 2 is chosen as optimal system design. The hybrid system in cases 2 is more reliable in terms of feeding preferences and continuity of electrical power supply as discussed earlier.

The study showed the importance of the addition of a conventional diesel generator to the components of hybrid system, not as an option but to ensure the continuous feeding of the electrical loads in some rare but critical condition especially for remote areas far from electrical grid.

\section{References}

Anagreh Y., \& Al-Ghzawi, A. (2013). Feasibility of utilizing renewable energy systems For a small hotel in Ajloun city, Jordan. Applied Energy, 103, 25-31. http://dx.doi.org/10.1016/j.apenergy.2012.10.008

Anagreh Y., \& Bataineh, A. (2011). Renewable energy potential assessment in Jordan. Renewable and Sustainable Energy Reviews, 15, 2232-2239. http://dx.doi.org/10.1016/j.rser.2011.02.010

Anayochukwu, A. V., \& Ndubueze, N. A. (2013). Potentials of Optimized Hybrid System In Powering Off-Grid Macro Base Transmitter Station Site. International Journal of renewable energy research, 3(4), 861-871.

Angelopoulos, K. (Glasgow 2004). Integration of Distributed Generation in Low Voltage Networks. Power Quality in Energy Systems and Environment. M.Sc. in Energy System and Environment.

Dunlop, J. P. (2010). Photovoltaic systems (2nd ed.). Illinois: American Technical Publishers Inc.

Fahmy, F. H., Ahmed, N. M., \& Farghally, H. M. (2012). Optimization of Renewable Energy Power System for Small Scale Brackish Reverse Osmosis Desalination Unit and a Tourism Motel in Egypt. Smart Grid and Renewable Energy, 3, 43-50. http://dx.doi.org/10.4236/sgre.2012.31006

Farret, F., \& Simoes, M. (Inc. IEEE PRESS, 2006). Integration of Alternative Sources of Energy. New Jersey: John Wiley and Sons.

Godson, J., Karthick, M., Muthukrishnan, T., \& Sivagamasundari, M. S. (2013). Solar PV-Wind Hybrid Power Generation System. International Journal of Advanced Research in Electrical, Electronics and Instrumentation Engineering, 2(11), 5350-5354.

Khare, A., \& Rangnekar, S. (2013). Optimal Sizing an SPV/Diesel/Battery Hybrid System for a Remote Railway Station in India. International journal of renewable Energy research, 3(3), 673-681.

Laboratory, N. (n.d.). The World's Leading Microgrid Modeling Software. Retrieved from www.homerenergy.com

Oğuz, Y., Oğuz H., Yabanova, I., Oguz, E., \& Kırkbaş, A. (2012). Efficiency Analysis of Isolated Wind-Photovoltaic Hybrid Power System with Battery Storage for Laboratory General Illumination for Education Purposes. International journal of renewable energy research, 2(3), 440-445.

Patel, M. (1999). Wind and Solar Power System. New York: CRC Press.

Rashidi, H., Niazi, S., \& Khorshidi, J. (2012). Optimal Sizing Method of Solar-Hydrogen Hybrid Energy System for Stand-alone Application Using Fuzzy Based Particle Swarm Optimization Algorithm. Australian 
Journal of Basic and Applied Sciences, 6(10), 249-256.

Shivrath, Y., Narayana, P. B., Thirumalasetty, S., \& Narsaiah, Dr. E. L. (2012). Design \& Integration of Wind-Solar Hybrid Energy System for Drip Irrigation Pumping Application. International Journal of Modern Engineering Research (IJMER), 2(4), 2947-2950.

Salmani, A., Sadeghzadeh, S. R., \& Naseh, M. (2014). Optimization and Sensitivity Analysis of a Hybrid System in KISH_IRAN. International Journal of Emerging Technology and Advanced Engineering, 4(1), 349-355.

Samantha, O., Ralph, S., \& Nicolai, K. (2007). Information Paper (Paris: OECD/ IEA, April 2007). Contribution of Renewable to Energy Security.

Trazouei, S., Tarazouei, F., \& Ghiamy, M. (2013). Optimal Design of a Hybrid Solar-Wind-Diesel Power System for Rural Electrification Using Imperialist Competitive Algorithm. International. Journal of renewable energy research, 3(2), 403-411.

Ventre, J. (2005). Photovoltaic systems engineering (2nd ed.). This edition published in the Taylor \& Francis e-Library.

\section{Copyrights}

Copyright for this article is retained by the author(s), with first publication rights granted to the journal.

This is an open-access article distributed under the terms and conditions of the Creative Commons Attribution license (http://creativecommons.org/licenses/by/3.0/). 